\title{
EFFECT OF THREE MINUTE STEP TEST ON COGNITION AMONG MEDICAL STUDENTS
}

\author{
Srista Manadhar ${ }^{1}$, Sunit Chettri ${ }^{1}$, Saugat Khatri ${ }^{1}$, Karishma Rajbhandari Pandey ${ }^{2}$, Nirmala Limbu ${ }^{2}$, Dharanidhar Baral ${ }^{3}$, \\ Dipesh Raj Pandey ${ }^{4}$ \\ Correspondence: karishma@bpkihs.edu \\ ${ }^{1}$ Bachelor of Medicine and Bachelor of Surgery, 5th year, B.P Koirala Institute of Health sciences, Nepal \\ ${ }^{2}$ Department of Basic and Clinical Physiology, B.P. Koirala Institute of Health Sciences, Nepal \\ ${ }^{3}$ Department of School of Public Health and Community Medicine, B.P. Koirala Institute of Health Sciences, Nepal \\ ${ }^{4}$ Department of Basic and Clinical Pharmacology, B.P. Koirala Institute of Health Sciences, Nepal
}

Article History:

Received: August 15, 2020

Accepted: June 20, 2021

Published: July 1, 2021

\section{Cite this as:}

Manadhar S, Chettri S, Khatri $S$,

Pandey KR, Limbu N, Baral D,

Pandey DP. Effect of three

minute step test on cognition

among medical students. Malang

Neurology Journal; 2021.7: 120-

124.

http://dx.doi.org/10.21776/ub.mnj .2021.007.02.7

\section{ABSTRACT}

Background: Regular physical exercise is linked to produce beneficial influence on cognitive functions. Cognition can be evaluated by Stroop test where a person's selective attention capacity, skills and processing speed are assessed. Limited work has been done to explore the acute effect of exercise on cognition.

Objective: To assess whether acute exposure to submaximal aerobic exercise of three minutes can bring changes in the cognitive function (selective attention and cognitive processing ability). The secondary objective was to assess the physical fitness index of medical students.

Methods: Twenty four apparently healthy third year male medical students of BPKIHS (B. P. Koirala Institute of Health Sciences) having mean age of $22.33 \pm 1.09$ years, body height and weight of $170.10 \pm 5.85 \mathrm{~cm}$ of $65.38 \pm 8.84 \mathrm{~kg}$ respectively were recruited. A computer based online version of Stroop Test was done to identify cognitive performance in resting sitting position. Then participants were asked to perform 3 min step test. A recovery time of 5 min was given post exercise and Stroop Test was assessed again. Statistical analysis was done using Paired $\mathrm{T}$ test. Data are expressed in mean and SD. Level of significance is considered at $\mathrm{p}<0.05$.

Results: The reaction time to Stroop Test was significantly reduced after acute physical exercise (before exercise $(43.37 \pm 7.7 \mathrm{~s})$ vs after exercise $(36.14 \pm 3.6 \mathrm{~s}), \mathrm{p}=0.001)$. However, no significant difference in the number of correct response to Stroop Test before $(19.71 \pm 1.08)$ and after $(19.79 \pm$ $0.51)$ the acute exercise $(\mathrm{p}=0.575)$ was observed.

Conclusion: Acute bout of aerobic physical exercise improves attention and execution aspects of cognitive function as measured by Stroop Test in young medical students.

Keywords: Cognition; medical students; Stroop test

\section{Introduction}

Medical students are young adults and are involved in vigorous mental activities. They have difficulty in managing a separate time schedule for instrumented and sophisticated sessions of gymnasium in order to prioritize studies. As an alternative Young Man's Christian Association (YMCA) three-minute step test can be done as an everyday exercise. It provides a submaximal measure of cardio-respiratory fitness. ${ }^{1}$ Exercises of such intensity have shown to improve working memory. ${ }^{2}$

The other advantage of YMCA is that it measures aerobic fitness level based on how quickly the heart rate returns to normal after exercise. ${ }^{3}$ Thus, providing the fitness index score. Knowing such score will motivate the unfit students to change their lifestyle and engage in physical activities.

Thus, this study was conducted with the aim to assess whether acute exposure to submaximal aerobic exercise of three minutes can bring changes in the cognitive function (selective attention and cognitive processing ability). The secondary objective was to assess the physical fitness index of medical students.

\section{Methods}

An analytical cross sectional study was conducted at Cardiovascular and Pulmonary Laboratory, Department of Basic and Clinical Physiology, B. P. Koirala Institute of Health Sciences (BPKIHS), Dharan, Nepal. The study was completed in a month (22nd April- 23rd May 2018) after receiving Ethical clearance from Department Research Unit (DRU) of Physiology which is under Institute Review Committee (IRC). The study was carried out in volunteering medical students after obtaining their informed written consent.

Subjects included for the study were healthy young male medical students of age between 17-30 yrs with normal eye sight or corrected to normal eyesight with normal color vision. Any male subject's with any acute or chronic illness or on medication for any kind of illness (any history of acute diseases, musculoskeletal diseases, psychiatric 
diseases, cardiovascular diseases, respiratory diseases, endocrine diseases) or having a history of alcohol abuse, use of neurotoxic drugs or agents were excluded. Female subjects were not enrolled in our study as menstrual cycle has been linked to affect cognition. However, results were conflicting. Some show improved performance at times of high estradiol levels whereas, others show no differences between luteal and follicular phases. ${ }^{4}$ For this reason and time constraint, females were excluded from the study.

The sample size was calculated as 24 . For its calculation we had referred the article of Debray P et al. entitled "Effect of step up exercise on cognitive attention with stroop test in Bengali male college students" which was published on 2015 in Asian Journal of Medical Sciences. ${ }^{5}$ The sample size estimation was done using Stroop test before exercise (mean \pm SD): $194.3( \pm 46.34) \mathrm{s}$ and Stroop test after exercise: $160.4( \pm 31.42)$ s from their study.

By comparing means of these two normally distributed samples of equal size using a two-sided test with significance level $\alpha$ and power $1-\beta$.

The sample size $(\mathrm{n})=\{(\delta 12+\delta 22)(\mathrm{Z} 1-\alpha / 2+\mathrm{Z} 1-\beta) 2\} / \Delta$

Here,

$\delta 1=$ Std. deviation in Stroop test before exercise

$\delta 2=$ Std. deviation in Stroop test after exercise

$\mathrm{Z} 1-\alpha / 2=1.96 \quad \mathrm{Z} 1-\beta=0.842$

$\Delta=$ mean before exercise - mean after exercise

Total sample size was $=21.38$

So, after calculation from above formula, the total sample size was 21.23. Ten percentage was added in it to reduce various types of biases, thus the total sample size calculated was 24.

The participants included were selected by Non- probability convenience sampling technique.

Subjects included were instructed to have normal sleep, the night before the recording. They were informed to have a light meal or breakfast 2 hours before recording. The study was carried out at Cardio-pulmonary lab during 10:00 am$12: 00$ noon at ambient temperature of $25-27^{\circ} \mathrm{C}$.

The subjects were allowed to rest for $10 \mathrm{~min}$ before recording their anthropometric (height and weight) and resting cardiovascular \{pulse rate (PR), systolic blood pressure (SBP), diastolic blood pressure (DBP) \} variables. Then subjects were exposed to modified Stroop Color and Word Test (SCWT) to determine their cognitive function. An online version ${ }^{6}$ was used to perform the Stroop test. Before performing, subjects were given full instructions about the procedure. They were seated in an adjustable computer chair and laptop screen was set according to their comfortable reading distance at around $50 \mathrm{~cm}$. Words were presented in the white background in the computer screen of 15 inches. The words were of readable size and font (Arial font and size 36). As a whole 15 incongruent and 5 congruent words (Black, Blue, Yellow, Green and Red) were presented randomly without any significant order in a color as stated or different. The subject had to press the mouse on the correct color option provided. He had to do it quickly and accurately. After 20 total words had been presented the calculated results were presented on the screen with correct color of the written word recognized.
The time taken to respond to total number of words was recorded manually using a stop watch.

Then subjects were allowed to rest for 10 minutes. Following it, YMCA 3 minute step test was done. This test measures the aerobic (cardiovascular) fitness level based on how quickly heart rate returns to normal after exercise. ${ }^{7}$ For this 13" inches height bench was used. Subjects performed stepping cycle of four-step cadence (up-up-down-down) on this bench. For male subjects it was done for twenty-four complete steps-ups per minute regulated with a metronome set at 96 beats per minute. The test was conducted for exactly three minutes. Before performing, they were given full instructions and were allowed for few seconds of practice session to familiarize with a stepping cadence. On completion, subjects were asked to remain standing for next 5 seconds. Their PR for 15 seconds was recorded and was noted as recovery heart rate (BPM). The details on the study design is provided in the figure 1 .

Subjects were selected based on eligibility criteria

$$
\text { Consent was taken }
$$

Anthropometric and cardiorespiratory variables were recorded

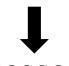

Cognitive function assessed using online version

$$
\begin{aligned}
& \text { Subjects perform } 3 \text { min step test } \\
& \text { Recovery heart rate was recorded after } 5 \mathrm{secs} \\
& \text { Cognitive function assessed using online version } \\
& \text { of Stroop test }
\end{aligned}
$$

Figure 1: Study Design

Physical fitness scores were calculated depending upon the recovery heart rate of the subject in three-Minutes Step Test. Calculation of physical fitness score was done according to the guidelines published by Young Man's Christian Association (YMCA) as given in Table No. $1 .^{8}$

\section{Statistical analysis and software used:}

Data entry was concurrently done in Microsoft excel with the ongoing study. The collected data were analyzed with SPSS software version 21. The observational results were represented as mean \pm SD. Regarding Inferential Statistics, Paired $\mathrm{T}$-test was applied to compare the variables before and after the exercise intervention.

\section{Results}

The mean age of the medical students enrolled for the study was $22.33 \pm 1.09$ years and mean body mass index was $22.53 \pm 2.27 \mathrm{~kg} / \mathrm{m}^{2}$. Their resting SBP, DBP and PR of the subjects are shown in Table 2.

After performing submaximal aerobic exercise for 3 minutes, the reaction time of stoop test was significantly reduced $(\mathrm{p}=0.001$, Table 3$)$. Whereas, there was no significant differences in the number of correct responses before and after the exercise $(\mathrm{p}=0.575)$. 
Table 1. Recovery Heart Rate ratings (BPM) for men, Based on Age (YMCA protocol)

\begin{tabular}{lllllll}
\hline Category of fitness & $18-25 y r s$ & $26-35 y r s$ & $36-45 y r s$ & $46-55 y r s$ & $56-65 y r s$ & $65+y r s$ \\
\hline Excellent & $50-76$ & $51-76$ & $49-76$ & $56-82$ & $60-77$ & $59-81$ \\
\hline Good & $79-84$ & $79-85$ & $80-88$ & $87-93$ & $86-94$ & $87-92$ \\
\hline Above Average & $88-93$ & $88-94$ & $92-88$ & $95-101$ & $97-100$ & $94-102$ \\
\hline Average & $95-100$ & $96-102$ & $100-105$ & $103-111$ & $103-109$ & $104-110$ \\
\hline Below average & $102-107$ & $104-110$ & $108-113$ & $113-119$ & $111-117$ & $114-118$ \\
\hline Poor & $111-119$ & $114-121$ & $116-124$ & $121-126$ & $119-128$ & $121-126$ \\
\hline Very Poor & $124-157$ & $126-161$ & $130-163$ & $131-159$ & $131-154$ & $130-151$ \\
\hline
\end{tabular}

Cognitive function using aforementioned Stroop Test was again assessed after a rest of $5 \mathrm{~min}$ after the aerobic exercise.

Table 2. Resting cardiovascular variables

\begin{tabular}{|c|c|}
\hline Variables & Mean \pm SD $(n=24)$ \\
\hline Pulse Rate (bpm) & $80.20 \pm 10.59$ \\
\hline Systolic Blood Pressure ( $\mathrm{mm}$ of $\mathrm{Hg}$ ) & $113.67 \pm 7.49$ \\
\hline Diastolic Blood Pressure ( $\mathrm{mm}$ of $\mathrm{Hg}$ ) & $74.75 \pm 4.93$ \\
\hline
\end{tabular}

Table 3. Comparison of cognition before and after acute aerobic submaximal exercise of 3 minutes

\begin{tabular}{llll}
\hline Variables & $\begin{array}{l}\text { Before 3 } \\
\text { minute step } \\
\text { test } \\
\text { Mean } \pm \text { SD } \\
(\mathbf{n = 2 4})\end{array}$ & $\begin{array}{l}\text { After 3 minute } \\
\text { step test } \\
\text { Mean } \pm \text { SD } \\
(\mathbf{n = 2 4})\end{array}$ & P value \\
\hline $\begin{array}{l}\text { Reaction time } \\
\text { in Stroop test } \\
(\text { sec) }\end{array}$ & $43.37 \pm 7.7$ & $36.14 \pm 3.6$ & 0.001 \\
\hline $\begin{array}{l}\text { Number of } \\
\text { correct } \\
\text { response in } \\
\text { SCW test }\end{array}$ & $19.71 \pm 1.08$ & $19.79 \pm 0.51$ & 0.575 \\
\hline
\end{tabular}

$\overline{S D}=$ Standard Deviation, $n=$ frequency; $p$ value $<0.05$ is considered statistically significant

The recovery HR of 24 medical students after exposure to acute submaximal aerobic exercise of 3 minutes is provided in Table 4. Based on YMCA guidelines (Table 1), their physical fitness level was determined using their recovery HR. It was found that maximum number of students had very poor fitness level.

Table 4. Recovery Heart Rate

\begin{tabular}{ll}
$\begin{array}{l}\text { Recovery Heart Rate }(\mathbf{H R}) \\
(\mathbf{b p m}), \text { Mean } \pm \text { SD }(\mathbf{n = 2 4})\end{array}$ & Number of students $(\boldsymbol{\%})$ \\
\hline $104 \pm 0$ & $2(8.33 \%)$ \\
\hline $113 \pm 5.03$ & $4(16.67 \%)$ \\
\hline $140.11 \pm 13.52$ & $18(75 \%)$ \\
\hline Total & $\mathbf{2 4}(\mathbf{1 0 0 \%})$ \\
\hline bpm $=$ Beats per min, $S D=$ Standard Deviation, $n=$ frequency
\end{tabular}

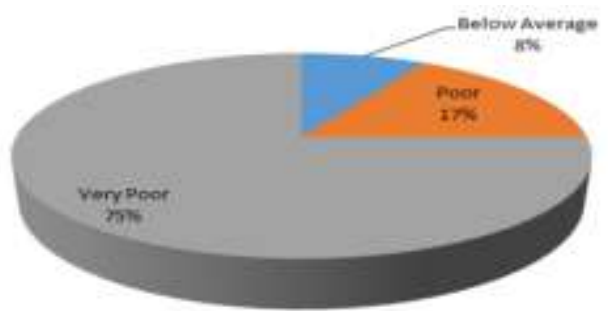

Figure 2. Physical Fitness Level of 24 medical students

\section{Discussion}

Our study used computer based modified online version of Stroop color and word test as a measure to assess the cognitive function in 24 healthy young male medical students of age $22.33 \pm 1.09$ years with BMI $22.53 \pm 2.27$ $\mathrm{kg} / \mathrm{m}^{2}$. There was significant $(\mathrm{p}<0.001)$ decrease in the rate at which the subjects performed the task after performing 3 minute step test (acute aerobic exercise). However, there was no significant difference in the number of correct responses before and after the exercise. Thus, response speed increases with no accompanying increase in error rates, suggesting that exercise produces a condition where individuals are able to perform tasks rapidly and efficiently. ${ }^{9} \quad$ Thus, acute bout of exercise improves cognitive performance by reducing the time for task completion without increasing the error. ${ }^{10,11,12,13}$ Such exercise elicits increased dorsolateral prefrontal cortex activation and improves cognitive performance. ${ }^{12}$ There is an improvement in the cerebral circulation and alteration of the synthesis and degradation of neurotransmitters. ${ }^{14}$ Also, plasma concentrations of norepinephrine are relatively high after exercise which is related to better memory. ${ }^{15}$

Gutin had mentioned about effect of duration of exercise on cognitive function. He pointed that exercise of $45 \mathrm{~s}$ to $2 \mathrm{~min}$, with heart rate of 90-120 bpm would have advantageous effect to cognition. Additionally, exercise of $6 \mathrm{~min}$ and causing more increase in HR would have ill effects in cognitive performance. ${ }^{16}$ However, in our study the duration of exercise was of 3 mins and $75 \%$ of the students had recovery HR of $140.11 \pm 13.52 \mathrm{bpm}$. So, exercise of this duration increasing $\mathrm{HR}>120 \mathrm{bpm}$ was able to increase the cognitive task performance without increasing the number of correct response. Thus, observing this we are in terms that exercise in acute form have little impact on the cognition. $^{17}$

Exercise exposed to the subjects in our study was not strenuous, which would otherwise have caused fatigue and improper brain functioning due to dehydration. ${ }^{18}$ This could be one of the reasons for not increasing the number in errors. Also, some studies have said that negligible effect in cognition is seen in the first 10 mins of exercise. Since the Stroop test was done following 5 mins rest after the exercise, it could be the reason for not obtaining any significant difference in number of errors. ${ }^{19}$ Still other studies have reported that acute intermediate intensity exercise has a strong effect on the speed of response in working memory tasks but a low effect on accuracy for performance. ${ }^{20}$ McMorris et al., 2011 suggested that it 
could be due to too much brain noise which affects precision adversely. ${ }^{20}$

YMCA three-minute step test is a test which provides a submaximal measure of cardio-respiratory fitness. In our study $8.3 \%$ of the participants had physical fitness in the category of below average, $16.7 \%$ were in poor category and remaining $75 \%$ (maximum) were under very poor category. Chatterjee S. et al., (2004) did a study in 60 college students (30 males and 30 females) in India using YMCA step test. ${ }^{21}$ They found that PFI of male subjects were in the category of below average and poor. The average recovery heart rate of our male subjects was 132.58 $\pm 17.9 \mathrm{bpm}$ whereas, in their study it was $112.95 \pm 8.94$ bpm. This reflects that our subjects have poorer recovery heart rate as compared to their study population. This might be because medical students in our set up are busy with their academic schedule and have less time to offer for their physical exercise. ${ }^{22}$ Or, it could be the students are embracing an unhealthy lifestyle and are not motivated to do physical activity.

\section{Implication}

Assessment of Physical fitness using "3 min step test" of the students possibly enrolled in all the levels of the institute must be done regularly to gauze physical and health. Also knowing one's fitness level will motivate one to be physically fit. This tes also enhances attention which is needed for better decision making. Hence we recommend the practice of such acute bout of physical exercise in lifestyle of every individual to improve the cognitive processing ability. Additionally, it is a cheap method to achieve such benefits.

\section{Limitations}

The study on female population could not be done due to different biology and time constraint. Another limitation was not recording the cardiac activity simultaneously, which would have given a better picture about cardiac autonomic activity. To add up in the limitation following were the potential biases a) Selection bias- due conventional sampling method of study, the sampling frame may not have represented the actual population which it should have ideally represented. b) Hawthorne effect- since the participants were aware that they were being observed, the way they would have responded during the time of recording might have unintentionally deviated away from its actual response.

\section{Conclusion}

Acute bout of aerobic physical exercise improves attention and execution aspects of cognitive function as measured by Stroop test in young medical students.

\section{Acknowledgement}

Our team is grateful for the enthusiastic participation by the study subjects. We would also like to appreciate the support from the Dept. of Basic and Clinical Physiology, BPKIHS.

\section{Conflict of Interest}

The authors declare there is no conflict of interest

\section{References}

1. Bohannon RW, Bubela DJ, Wang Y-C, et al. Sixminute walk test vs three-minute step test for measuring functional endurance. J strength Cond Res; 2015; 29(11):3240-3244.

DOI: 10.1519/JSC.0000000000000253

2. Bhattacharyya D, Sen S, Chatterjee S, et al. Effect of queen's college step test on cognitive performance among young adults. J Biol Exer; 2017. 13: 59-75. DOI: $10.4127 /$ jbe.2017.0116

3. Jurca R, Jackson AS, LaMonte MJ, et al. Assessing cardiorespiratory fitness without performing exercise testing. Am J Prev Me; 2005. 29(3): 185-193.

DOI: 10.1016/j.amepre.2005.06.004

4. Sundström Poromaa I, Gingnell M. Menstrual cycle influence on cognitive function and emotion processing-from a reproductive perspective. Front Neurosci; 2014. 8:380.

DOI: $10.3389 /$ fnins.2014.00380

5. Debray P, Biswas S, Biswas P, et al. Effect of step up exercise on cognitive attention with stroop test in Bengali male college students. Asian J Med Sci; 2015. 6(6):66-69.

DOI: https://doi.org/10.3126/ajms.v6i6.12602

6. Stroop Test Online.com - (C) 2005 - 2018. Accessed on May 15, 2018. http://www.onlinestrooptest.com/

7. Vidoni ED, Mattlage A, Mahnken J, et al. Validity of the step test for exercise prescription: No extension to a larger age range. J Aging Phys Act; 2013. 21(4): 444-454. DOI:10.1123/japa21.4.444

8. Anderson J. YMCA bench step test for cardiovascular fitness. Published; 2008. Accessed April 27, 2018. Avalaible from: https://thehubeduproduction.s3.amazonaws.com/uploads/3/fd00fae87453-45bf-96bb705135c0ba27/YMCA_Bench_Step_Test_for_Cardio vascular_Fitness.pdf.

9. Gondola JC. The effects of a single bout of aerobic dancing on selected tests of creativity. J Soc Behav Personal; 1987. 2(2): 275-278. [Google Scholar]

10. Hillman CH, Pontifex MB, Raine LB, et al. The effect of acute treadmill walking on cognitive control and academic achievement in preadolescent children. Neuroscience; 2009. 159(3): 1044-1054. doi:10.1016/j.neuroscience.2009.01.057

11. Pontifex MB, Saliba BJ, Raine LB, et al. Exercise improves behavioral, neurocognitive, and scholastic performance in children with attentiondeficit/hyperactivity disorder. J Pediat; 2013. 162(3): 543-551. DOI: 10.1016/j.jpeds.2012.08.036

12. Yanagisawa H, Dan I, Tsuzuki D, et al. Acute moderate exercise elicits increased dorsolateral prefrontal activation and improves cognitive performance with Stroop test. Neuroimage; 2010. 50(4): 1702-1710.

DOI: 10.1016/j.neuroimage.2009.12.023

13. Kamijo K, Nishihira Y, Higashiura $T$, et al. The interactive effect of exercise intensity and task difficulty on human cognitive processing. Int $\mathrm{J}$ Psychophysiol; 2007. 65(2): 114-121.

DOI:

10.1016/j.ijpsycho.2007.04.001 
14. Kashihara K, Maruyama T, Murota M, et al. Positive effects of acute and moderate physical exercise on cognitive function. J Physiol Anthropol; 2009. 28(4): 155-164. DOI: 10.2114/jpa2.28.155

15. Antunes HKM, Santos RF, Cassilhas R, et al. Reviewing on physical exercise and the cognitive function. Rev Bras Med do Esporte; 2006. 12: 108114. DOI: $10.1590 / \mathrm{S} 1517-86922006000200011$

16. Gutin B. Exercise-Induced Activation and human performance: A review. Res Quarterly Am Assoc Heal Phys Educ Recreat; 1973. 44:256-268.

DOI: doi.org/10.1080/10671188.1973.10615204

17. Etnier J, Salazar W, Landers D, et al. The influence of physical fitness and exercise upon cognitive functioning: A meta-analysis. J Sport Exerc Psychol; 1997. 19(3):249-74.

DOI: doi.org/10.1123/jsep.19.3.249

18. Cian C, Barraud PA, Melin B, et al. Effects of fluid ingestion on cognitive function after heat stress or exercise-induced dehydration. Int J Psychophysiol
Off J Int Organ Psychophysiol; 2001. 42(3):243-251. DOI: 10.1016/s0167-8760(01)00142-8

19. Chang YK, Labban JD, Gapin JI, et al. The effects of acute exercise on cognitive performance: A metaanalysis. Brain Res; 2012. 1453:87-101. DOI: 10.1016/j.brainres.2012.02.068.

20. McMorris T, Sproule J, Turner A, et al. Acute, intermediate intensity exercise, and speed and accuracy in working memory tasks: A meta-analytical comparison of effects. Physiol Behav; 2011. 102:421428. DOI: doi.org/10.1016/j.physbeh.2010.12.007

21. Chatterjee S, Chatterjee P, Mukherjee PS, et al. Validity of Queen's College step test for use with young Indian men. Br J Sports Med; 2004. 38(3): 289-291. DOI: 10.1136/bjsm.2002.002212

22. Rivarti AW, Herawati L, Hidayati HB. Exercise prevents age-related memory decline: the role of neurotrophic factors. MNJ; 2020.6(2): 88-94. DOI: 10.21776/ub.mnj.2020.006.02.8. 